\title{
Analysis on the Spatiotemporal Characteristics of the Postearthquake Reconstruction Efficiency of the Extremely Earthquake-Stricken Areas by the Wenchuan Earthquake Based on the DEA-Malmquist Index
}

\author{
Pin Lv $\mathbb{D}^{1},{ }^{1}$ Bin Liu $\mathbb{D},{ }^{1,2}$ Mingkang Yuan $\mathbb{D},{ }^{1}$ Suyue Han $\mathbb{D}^{1},{ }^{1}$ Di Zhang $\mathbb{D}^{1},{ }^{1}$ and Lv Zhang $\mathbb{D}^{3}$ \\ ${ }^{1}$ College of Management Science, Chengdu University of Technology, Chengdu 610059, China \\ ${ }^{2}$ Geomathematics Key Laboratory of Sichuan Province, Chengdu University of Technology, Chengdu 610059, China \\ ${ }^{3}$ Sichuan Institute of Land Science and Technology (Sichuan Center of Satellite Application Technology), Chengdu 610045, China
}

Correspondence should be addressed to Bin Liu; liubincim@163.com and Lv Zhang; lvlv_2018@163.com

Received 25 May 2020; Revised 14 July 2020; Accepted 4 September 2020; Published 19 October 2020

Academic Editor: Ricardo López-Ruiz

Copyright (C) 2020 Pin Lv et al. This is an open access article distributed under the Creative Commons Attribution License, which permits unrestricted use, distribution, and reproduction in any medium, provided the original work is properly cited.

\begin{abstract}
The Wenchuan earthquake, which occurred on May 12, 2008, caused a large number of casualties and substantial property losses. Postearthquake reconstruction is a complex and systematic project, the core of which is to enable the residents of the earthquake-stricken areas to resume normal productivity and life as soon as possible. This paper aims to evaluate the efficiency of postearthquake reconstruction in extremely earthquake-stricken areas. From the perspective of the inputs and outputs, the DEA-Malmquist index was used to construct a reconstruction efficiency evaluation model for the extremely stricken areas. Reconstruction efficiencies are analyzed for 10 areas that were severely impacted by the Wenchuan earthquake. Finally, three major disaster-pregnancy environmental factors, namely, including topography, fault zones, and river systems, are selected. Based on the temporal trend of reconstruction efficiency, the degree of correlation between the postearthquake reconstruction efficiency fluctuation and the three major disaster-pregnancy environmental factors is analyzed. The study results show that the overall reconstruction efficiency of the 10 extremely earthquake-stricken areas was relatively high. In 2011 , the reconstruction efficiency basically returned the areas to preearthquake levels, and there was a small fluctuation in efficiency due to the effects of earthquake-induced hazards and the reduction of external forces. Spatially, the reconstruction efficiencies of the 10 extremely stricken areas do not show a "convergence effect," and the reconstruction efficiencies were closely related to the characteristics of the resources in the extremely stricken areas. In terms of the main disaster-pregnancy environment, the terrain complexity is most closely related to fluctuation of reconstruction efficiency, with a correlation coefficient of 0.9975 , followed by river network density and the lowest fault density. Therefore, to improve the reconstruction efficiency of the extremely earthquakestricken areas, the adjustment measures that promote local advantages should be fully utilized to mitigate the lasting effects of earthquake-induced hazards.
\end{abstract}

\section{Introduction}

There are many continental earthquakes every year in the world, among which continental earthquakes in China account for approximately 33\% of the global continental earthquakes. According to incomplete statistics, the death toll from the earthquakes that occurred in China from 1993 to 2016 accounted for approximately $50 \%$ of all global earthquake deaths. At the same time, more than two-thirds of the provinces in mainland China have been affected by the earthquakes and hundreds of millions of people have been affected [1]. The Longmenshan fault zone is in one of the mountain ranges in China, and although it has one of the largest zones of steep terrain in the world, it is still active. An earthquake of magnitude 8.0 occurred in Wenchuan County, in the midnorthern part of the Longmenshan fault 
zone, on May $12^{\text {th }}, 2008$. This was one of the most large-scale destructive earthquakes in Chinese history in addition to the Tangshan earthquake. In addition to causing direct losses such as heavy casualties and substantial property losses, the earthquake also caused a large number of earthquake-induced hazards, such as landslides, collapses, debris flows, and other geological disasters, and the losses caused by earthquake-related geological hazards in earthquakestricken areas have far exceeded losses caused by earthquakes themselves [2,3]. Therefore, the evaluation of the reconstruction efficiency of extremely earthquake-stricken areas is helpful in providing a scientific basis for making postearthquake reconstruction decisions.

Postearthquake reconstruction is an important effort to ensure normal production and life in earthquake-stricken areas. Many scholars have studied postearthquake ecological environments and infrastructure. From the perspective of the ecological environment, Fan et al. studied the impact of earthquakes on the environment and assessed the value of the natural resources in earthquake-stricken areas for the sustainable development of the reconstructed areas [4]. Zhi integrated remote sensing data and field surveys to assess the ecological impact of an earthquake and indicated that ecosystem recovery should be one of the priorities of the reconstruction plans in earthquake-stricken areas [5]. Wang analyzed and compared the ecological environment before and after the earthquake, summarized the damage and ecological risks caused by the earthquake, and put forward suggestions for postearthquake reconstruction [6]. In terms of the reconstruction performance, Abramson et al. proposed a social-ecological model to evaluate the performance of postearthquake reconstruction that combined housing stability, economic stability, physical health, mental health, and social adaptability [7]. Burton et al. analyzed remote sensing images of the same location at different times and constructed a performance evaluation model for the reconstruction process and reconstruction results [8]. Bates et al. established a measurement framework for hazard impacts and recovery $[9,10]$. In terms of infrastructure, Liu et al. analyzed and compared two modes of postearthquake reconstruction: in situ reconstruction and reallocated reconstruction [11]. Polese et al. used a logistic regression to find demolition probability and evaluate building reparability after damaging earthquakes [12]. In addition, Chang et al. provided evidence of the inherent resource bottlenecks in postearthquake reconstruction [13]. Taking the Wenchuan earthquake as a case study, Tang revealed that fragile infrastructure, degraded ecosystems, and vulnerable social groups were closely related and existed in a large number of rural areas in inland China [14]. In summary, postearthquake reconstruction is a large systematic project that needs to be studied from different aspects, such as societal, economic, and ecological perspectives.

Postearthquake reconstruction is a long-term process, and measuring the reconstruction efficiency of earthquakestricken areas is conducive to sustainable development; therefore, it is very important to construct an evaluation model of postearthquake reconstruction efficiency. Data envelopment analysis (DEA) is based on the concept of "relative efficiency." According to the principle of multiple inputs and multiple outputs, the mathematical model of comprehensive efficiency of each decision-making unit (DMU) was obtained. The Malmquist productivity index is a consumption index proposed by Malmquist and subsequently developed into a new index that measures the progress of the multi-input and multioutput productivity of the DMU [15]. Shepherd defined the Malmquist index by establishing a distance function [16]. Caves et al. introduced the Malmquist index into a production analysis, constructed the productivity index through the ratio of the distance function to measure the change in the total factor productivity (TFP), and named it the Malmquist productivity index [17]. The above Malmquist index is a theoretical index, but Fare changed the Malmquist productivity index from a theoretical index to an empirical index based on the DEA proposed by Charnes et al. [18, 19]. Fare et al. further decomposed the Malmquist index into technical efficiency variation, technological progress, and scale efficiency variation [20]. At the same time, the DEA-Malmquist index has been widely used in various fields. Linna used the input and output panel data from major Finnish hospitals from 1988 to 1994 to analyze the cost efficiency and productivity with the DEA-Malmquist index [21]. Ventura et al. used the DEAMalmquist index to calculate the efficiency of the panel data for the Spanish pharmaceutical industry from 1994 to 2000 [22]. Kortelainen used the DEA-Malmquist index for the dynamic analysis of environmental performance [23]. Assaf and Barros conducted a Malmquist index efficiency analysis of the corrected deviations in the performance of the hospitality industry [24]. Johannes and Semida used the DEAMalmquist index to evaluate the energy-use efficiency of the European Union from 2000 to 2010 [25]. Varmaghani et al. used the DEA-Malmquist index to analyze the dynamic productivity of 21 pharmaceutical companies in Iran from 2000 to 2013 and concluded that TFP could be improved through greater attention to the improvement of productivity [26]. Amani et al. used the DEA-Malmquist index to analyze the performance of Iran's power industry over two years [27]. In conclusion, the DEA-Malmquist index has been widely applied to the dynamic efficiency evaluation of banking, real estate, logistics, and other industries.

This paper is organized as follows: Section 1 outlines the postearthquake reconstruction and study process in which the DEA-Malmquist is applied to the efficiency evaluation; Section 2 presents ideas and methods for the reconstruction efficiency evaluation model in extremely earthquake-stricken areas; Section 3 takes 10 extremely earthquake-stricken areas from the Wenchuan earthquake as the research objects and analyzes the temporal patterns and the reasons for the differences in the reconstruction efficiency of extremely earthquake-stricken areas after the 2008 earthquake; Section 4 analyzes the correlation between the three main disaster-pregnancy environmental factors of terrain complexity, fault density, and river network density in the extremely earthquake-stricken areas and the fluctuation of reconstruction efficiency after the disaster; and Section 5 presents the study's discussion and conclusions. 


\section{Model of Reconstruction Efficiency Evaluation in Extremely Earthquake- Stricken Areas}

Aiming to evaluate the efficiency of postearthquake reconstruction in the extremely earthquake-stricken areas, this paper focuses on the perspective of the effects of earthquake-induced hazards (earthquake-induced hazards are defined as follows: it is made up of the phenomena that are induced by earthquakes, such as collapses, landslides, and other earthquake-induced hazards, which create a large quantity of loose debris that provides landslides, debris flow, and other earthquake-induced hazards with sufficient source, and increase the intensity of the earthquake-induced hazards.) Because long-lasting earthquakes happen in the areas surrounding the earthquakestricken areas with uncertain frequencies [28], from the perspective of postearthquake "input-output" analysis, an evaluation model of reconstruction efficiency based on the DEAMalmquist index was constructed that considered the influence of postearthquake reconstruction measurements of the reconstruction process in the extremely earthquake-stricken areas by building "input and output" index systems. The temporal trends and spatial patterns of the postearthquake reconstruction efficiencies were analyzed through the total factor analysis of the extremely stricken earthquake areas. Moreover, the correlation between the reconstruction efficiency of the extremely earthquake-stricken areas and the spatial distribution characteristics of the main disaster-pregnancy environment: topography, fault zones, and river systems, is analyzed (Figure 1).

\subsection{Indicator System for the Evaluation of Reconstruction} Efficiency. Postearthquake reconstruction is a complex and systematic project, and it will be helpful for postearthquake reconstruction to determine the differences among the extremely earthquake-stricken areas. This study, from the perspective of "input and output," analyzed the influence that postearthquake reconstruction investment (such as external aid) has on the reconstruction process and evaluated the reconstruction efficiency of the extremely earthquake-stricken areas. In detail, postearthquake investments, such as the whole social fixed assets, highway mileage, number of mobile phones, number of students at the secondary schools, number of hospital beds, and number of hidden dangers from earthquake-induced hazards, are major reflections of the infrastructure, education, medical treatment, traffic, communication, treatment of earthquakeinduced hazards, and other investments, which are the inputs. The GDP per capita, degree of deviation of the industrial structure, and the vegetation coverage are used to reflect the social, economic, and ecological reconstruction performances, which are the outputs. The meanings of the "input and output" indicators are shown in Table 1.

2.2. DEA-Malmquist. The DEA-Malmquist model is mainly used to measure the productivity efficiency of several DMUs with the same types of multi-inputs and multioutputs, and it can be used to vertically evaluate the efficiency of each DMU. The Malmquist index was first proposed by Malmquist [15]. Caves et al. first applied the index to the measurement of changes in productivity [17]. Subsequently, Fare et al. combined the DEA theory established by Charnes et al. with the Malmquist index [18, 19] and has the following basic principles.

From period $t$ to $t+1$, the Malmquist index, which measures the TFP growth from the perspective of output, can be expressed as follows:

$$
M_{o}\left(x_{t+1}, y_{t+1}, x_{t}, y_{t}\right)=\left[\frac{D_{o}^{t}\left(x_{t+1}, y_{t+1}\right)}{D_{o}^{t}\left(x_{t}, y_{t}\right)} \times \frac{D_{o}^{t+1}\left(x_{t+1}, y_{t+1}\right)}{D_{o}^{t+1}\left(x_{t}, y_{t}\right)}\right]^{1 / 2},
$$

where $\left(x_{t+1}, y_{t+1}\right)$ and $\left(x_{t}, y_{t}\right)$ separately represent the input and output vectors of periods $t+1$ and $t$. With the optimal technology in time $t\left(\mathrm{~T}_{t}\right)$ as the reference standard, $D_{o}^{t}$ and $D_{o}^{t+1}$, respectively, represent the distance function from time $t$ and time $t+1$ to the forefront of the optimal technology.

With the optimal technology $\left(\mathrm{T}_{t}\right)$ in period $t$ as a reference, the output-based Malmquist index can be expressed as follows:

$$
M_{0}^{t}\left(x_{t+1}, y_{t+1}, x_{t}, y_{t}\right)=\frac{D_{o}^{t}\left(x_{t+1}, y_{t+1}\right)}{D_{o}^{t}\left(x_{t}, y_{t}\right)} .
$$

With the optimal technology $\left(\mathrm{T}_{t+1}\right)$ in period $t+1$ as a reference, the output-based Malmquist index can be expressed as follows:

$$
M_{0}^{t+1}\left(x_{t+1}, y_{t+1}, x_{t}, y_{t}\right)=\frac{D_{o}^{t+1}\left(x_{t+1}, y_{t+1}\right)}{D_{o}^{t+1}\left(x_{t}, y_{t}\right)} .
$$

To avoid the difference caused by the randomness of the period selection, according to the construction method of Fisher's ideal index, the geometric average of equations (2) and (3) was used as the Malmquist index to measure the change in productivity from $t$ to $t+1$. When the index is more than 1 , it indicates that TFP increased from $t$ to $t+1$. When the index is less than 1, it indicates that TFP decreased from $t$ to $t+1$. When it is equal to 1 , it indicates that TFP remained unchanged. Moreover, $M_{o}$ can be further decomposed as follows:

$$
M_{o}\left(x_{t+1}, y_{t+1}, x_{t}, y_{t}\right)=\underbrace{\frac{D_{o}^{t+1}\left(x_{t+1}, y_{t+1}\right)}{D_{o}^{t}\left(x_{t}, y_{t}\right)}}_{\text {Change in efficiency }} \times \underbrace{\left[\frac{D_{o}^{t}\left(x_{t+1}, y_{t+1}\right)}{D_{o}^{t+1}\left(x_{t+1}, y_{t+1}\right)} \times \frac{D_{o}^{t}\left(x_{t}, y_{t}\right)}{D_{o}^{t+1}\left(x_{t}, y_{t}\right)}\right]^{1 / 2}}_{\text {Technical change }}=\mathrm{EFF} \times \mathrm{TEC},
$$




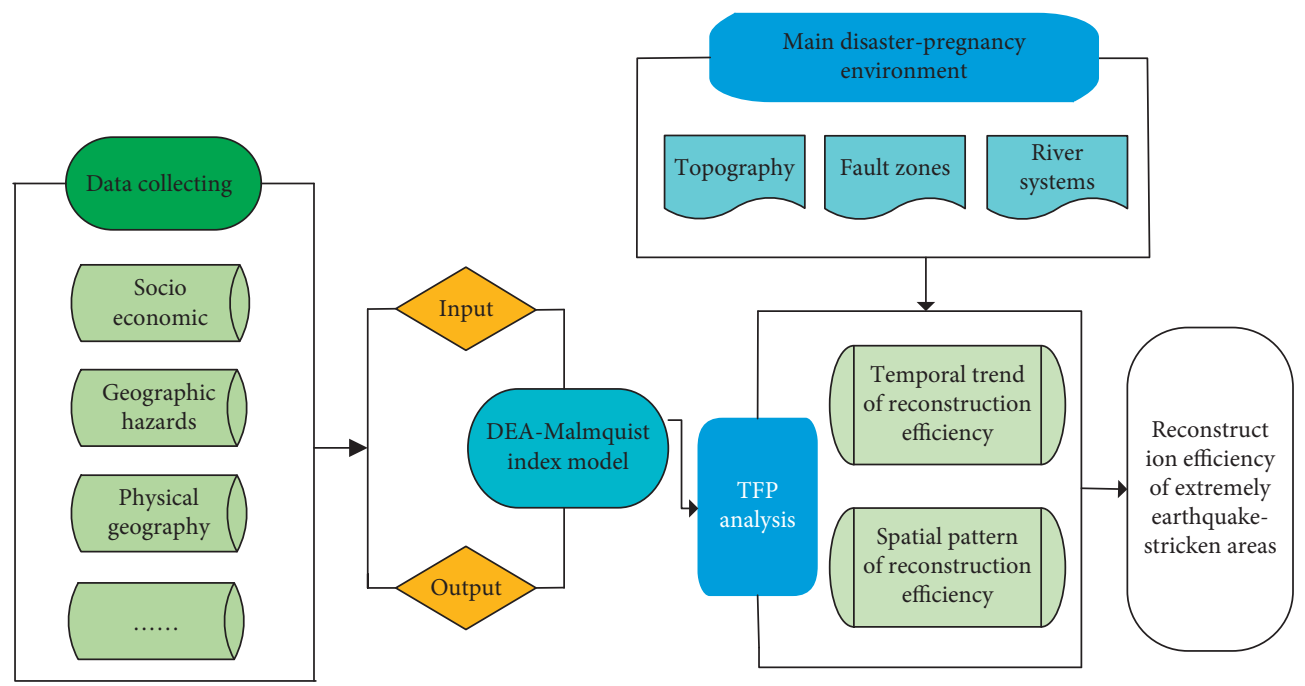

FIGURE 1: Framework of the reconstruction efficiency evaluation.

TABLE 1: Postearthquake reconstruction "input and output" indicators.

\begin{tabular}{|c|c|c|c|}
\hline & Indicators & Description & Data sources \\
\hline \multirow{6}{*}{ Input $(I)$} & Investment of the whole social fixed assets $\left(I_{1}\right)$ & Reflects input in infrastructure & $\begin{array}{l}\text { Statistical } \\
\text { yearbook }\end{array}$ \\
\hline & Highway mileage $\left(I_{2}\right)$ & Reflects input in traffic & $\begin{array}{l}\text { Statistical } \\
\text { yearbook }\end{array}$ \\
\hline & The number of the mobile phones $\left(I_{3}\right)$ & Reflects input in communication & $\begin{array}{l}\text { Statistical } \\
\text { yearbook }\end{array}$ \\
\hline & The number of staff at the secondary school $\left(I_{4}\right)$ & Reflects input in education & $\begin{array}{l}\text { Statistical } \\
\text { yearbook }\end{array}$ \\
\hline & The number of hospital beds $\left(I_{5}\right)$ & Reflects input in medical treatment & $\begin{array}{l}\text { Statistical } \\
\text { yearbook }\end{array}$ \\
\hline & $\begin{array}{c}\text { The number of hidden dangers from earthquake- } \\
\text { induced hazards }\left(I_{6}\right)\end{array}$ & $\begin{array}{l}\text { Reflects input in the management of earthquake- } \\
\text { induced hazards }\end{array}$ & $\begin{array}{l}\text { Remote sensing } \\
\text { data }\end{array}$ \\
\hline \multirow{3}{*}{$\begin{array}{l}\text { Output } \\
(O)\end{array}$} & GDP per capita $\left(O_{1}\right)$ & Reflects performance in social recovery & $\begin{array}{l}\text { Statistical } \\
\text { yearbook }\end{array}$ \\
\hline & Degree of deviation of the industrial structure $\left(\mathrm{O}_{2}\right)$ & Reflects performance in economic recovery & $\begin{array}{l}\text { Statistical } \\
\text { yearbook }\end{array}$ \\
\hline & Vegetation coverage rate $\left(\mathrm{O}_{3}\right)$ & Reflects performance in ecological recovery & $\begin{array}{l}\text { Remote sensing } \\
\text { data }\end{array}$ \\
\hline
\end{tabular}

where the components of the Malmquist index are built as distance ratios. The first component describes the changes in efficiency from $t$ to $t+1$; this factor is called the change in efficiency (EFF). The second component is referred to as technical change (TEC) and represents the shift in technology from the old to the new frontier between $t$ and $t+1$. Malmquist index values that are higher than 1 represent improvements in productivity; otherwise, they indicate a decrease in productivity.

\section{Analysis of Postearthquake Reconstruction Efficiency in Extremely Earthquake- Stricken Areas}

3.1. Overview of the Study Area. The "5.12" Wenchuan earthquake in 2008 occurred in the midnorthern part of the Longmenshan fault zone. Wenchuan County, Beichuan
County, Qingchuan County, Maoxian, Anxian, Mianzhu city, Shifang city, Dujiangyan city, Pingwu County, and Pengzhou city suffered considerable damage from the earthquake and were considered the extremely earthquakestricken areas (Figure 2). The total population of these 10 extremely earthquake-stricken areas was up to 3.5 million people. The Minjiang River and Fujiang River run through the extremely earthquake-stricken areas, and the regional topography is relatively complex. Moreover, due to the adjoining earthquake centers and the proximity to the Longmenshan central fault zones, the socioeconomic development of extremely stricken earthquake areas has been severely restricted. According to the distribution of earthquake damage and intensity, combined with the availability and quality of data, this paper uses 10 extremely earthquakestricken areas as the study areas to analyze the postearthquake reconstruction efficiency, and it provides a 


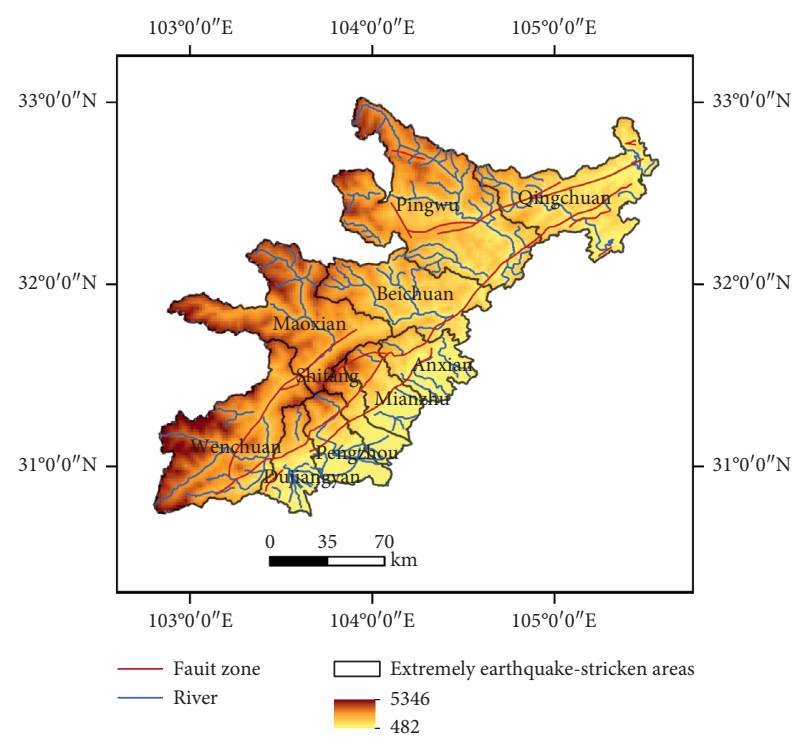

Figure 2: Geographic location of the study area.

reference for studying the postearthquake reconstruction efficiency of other similar mountainous earthquake disaster areas.

\subsection{Global Analysis of the Temporal Trends in Postearthquake} Reconstruction Efficiency in Extremely Earthquake-Stricken Areas. To more comprehensively analyze the temporal trends of postearthquake reconstruction efficiency in the extremely earthquake-stricken areas, this paper collects data from before and after the 2008 earthquake (2007-2017) in 10 extremely earthquake-stricken areas, to visualize the changes in "inputs" and "outputs" before and after the earthquake in extremely earthquake-stricken areas. Through statistical yearbooks, data on social fixed assets investment, school construction, hospital building, road building, and service facilities in extremely earthquake-stricken areas can be collected. In addition, the number of hidden dangers from earthquake-induced hazards and vegetation coverage rate are all derived from MODIS remote sensing data. Combined with the reconstruction efficiency model mentioned in Section 2, the reconstruction efficiencies of 10 extremely earthquake-stricken areas were analyzed, and for 2007 to 2017, the TFP, EFF, and TEC of the extremely stricken earthquake areas were computed. The results are shown in Figure 3.

The following trends can be seen from the results of the TFP from 2007 to 2017 in Figure 3:

(1) According to the change in the TFP after the earthquake in 2008, the average value of the TFP in the 10 extremely earthquake-stricken areas from 2007 to 2017 was 0.916 , and there were areas for improvement in $8.4 \%$. Combined with the results of the TEC, the dependence of the TFP on technology progress was obvious.

(2) The TFP of the 10 extremely earthquake-stricken areas fell sharply after the 2008 earthquake. As a

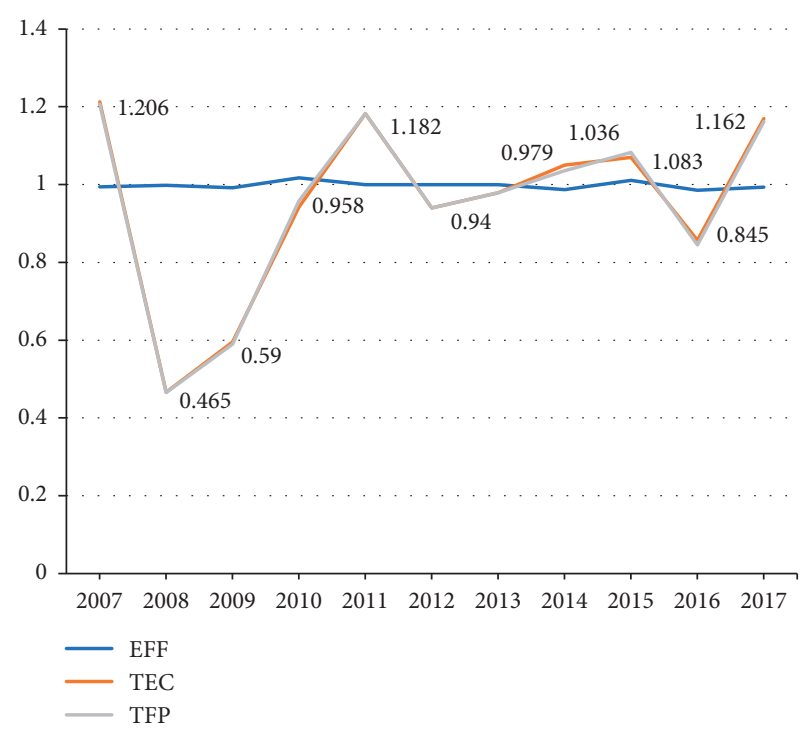

Figure 3: Changes in the TFP index.

result of the postearthquake reconstruction in the form of social investments in fixed assets, schools, hospital building construction, road building, service facilities, and heavy inputs in the treatment of hidden dangers of earthquake-induced hazards, the TFP of the extremely earthquake-stricken areas appeared to exhibit an approximately linear growth trend four years after the earthquake (before 2011). This stage was mainly affected by external forces (external aid, etc.). After 2012, the TFP fluctuated. On the one hand, it was because of the self-adjustment (industrial adjustment, etc.) of the extremely earthquakestricken areas, while on the other hand, it was also due to the gradual dwindling of external forces.

(3) Earthquake-induced hazards (caused by the effects of earthquake-induced hazards) occurred frequently in the extremely earthquake-stricken areas, and several severe debris flow hazards occurred separately in 2010, 2013, and 2017 with values of "8.13," "7.9," and "7.8," respectively, which had significant impacts on the regional socioeconomy [29]. Figure 3 shows that, in 2008, when the earthquake occurred, the TFP was 0.465 , which was the lowest level in that year, but it soon rose sharply to a peak at 1.182. After 2011, the TFP fluctuated slightly around 1; this fluctuation corresponded to several extremely heavy earthquake-induced hazards, which were greatly influenced by the effects of earthquake-induced hazards. The extremely earthquake-stricken areas are relatively "fragile" after the earthquake, and a lone external force is not able to strengthen the ability to resist earthquake-induced hazards.

3.3. Analysis of the Differences in Postearthquake Reconstruction Efficiency in Extremely Earthquake-Stricken Areas. Using temporal trend analysis, the TFPs of the 10 extremely earthquake-stricken areas were calculated separately to allow 
comparison of the spatial differences in the TFPs of the 10 extremely earthquake-stricken areas that were in the process of reconstruction. The results are shown in Figure 4. During reconstruction, the TFPs of the 10 extremely stricken earthquake areas did not exhibit a "convergence effect" as a whole.

According to the division results in Figure 4, we can see that there are four fluctuations in the TFPs of the $10 \mathrm{ex}$ tremely earthquake-stricken areas from 2007 to 2017, and combined with the proportion of the three industries in the 10 extremely earthquake-stricken areas from 2007 to 2017, the following results are obtained:

(1) The first category: Shifang, Mianzhu, and Pengzhou. These three cities were excellent industrial cities in Sichuan Province before the earthquake, and it can be seen from Figure 5 that the proportion of secondary industries in these three areas exceeded 50\% before and after the earthquake. Combined with Figure 4, the TFP of these three areas fell sharply in a short period of time after the 2008 earthquake, benefiting from the geographical advantages of the three areas, which have unique policy advantages and advantages in science and technology resources, focusing on the development of special industries such as medicine, alcohol, and machinery. The secondary industries were rapidly restored, coupled with the protection of the ecological environment, and are less affected by earthquake-induced hazards; therefore, the three areas show a strong ability to cope with earthquake-induced hazards.

(2) The second category: Dujiangyan. As a tourism-reliant city, Dujiangyan leads the cities of Sichuan Province with its third industry. Due to the frequent occurrence of earthquake-induced hazards, such as landslides and debris flow, the earthquake-induced hazards have a greater affect, and it can be seen from Figure 4 that the TFP exhibited two large fluctuations. It can be seen from Figure 6 that the proportion of tertiary industry is more than $50 \%$, while at the same time, its secondary industries have shown strong development momentum, which is mainly because the region is located in Chengdu's half hour economic circle; therefore, the government and society have invested heavily in technology, construction, and other industries in Dujiangyan. Combined with the fluctuation of TFP, it shows that Dujiangyan City, which is supported by the tertiary industry, is susceptible to earthquake-induced hazards.

(3) The third category: Qingchuan, Beichuan, Pingwu, and Anxian. It can be seen from Figure 7 that the three industries in these four areas account for approximately $1 / 3$ each, of which primary industry showed a significant downward trend after the earthquake, combined with Figure 4, indicating that TFP steadily increased, due to external forces such as external assistance in the first three years after the earthquake, but after the external force has subsided, TFP fell sharply. This shows that mountainous areas with primary industry as the main industry are susceptible to earthquake-induced hazards. From the proportion of the three industries, one can determine that the local government optimized and adjusted the industrial structure after the earthquake; therefore, its economic development gradually tilted towards the secondary and tertiary industries to promote the local social and economic development.

(4) The fourth category: Maoxian and Wenchuan. The economic and ecological damage in these two areas after the earthquake were severe, and postearthquake reconstruction was more difficult here than in other areas. It can be seen from Figure 4 that, during the postearthquake reconstruction process, the TFP in the two areas fluctuates with the occurrence of earthquake-induced hazards in high-risk years $(2010,2013$, and 2017). Moreover, it can be seen from Figure 8 that Wenchuan County vigorously developed its low-carbon industries, and its secondary industry as a pillar industry exceeds $60 \%$. In addition, since the two areas are adjacent to the epicenter, there are many external factors. Although the TFP fluctuated after the earthquake, the amplitude is small, indicating that these two areas were less affected by the earthquake-induced hazards.

\section{Correlation Analysis between the Main Disaster-Pregnancy Environmental and Reconstruction Efficiency in the Extremely Earthquake-Stricken Areas}

Due to the persistence of the earthquake geological disaster effect (Huang, 2011), the economic and social development of the extremely earthquake-stricken areas will be affected by such a disaster for a long period of time. At the same time, the reasons for the reconstruction efficiency of the extremely earthquake-stricken areas were varied, and the geographical location of extremely earthquake-stricken areas is one of the important factors. Therefore, this paper considers the differences in the disaster-pregnancy environment of the extremely earthquake-stricken areas and extracts three major disaster-pregnancy environmental factors, namely, the topography, fault zones, and river systems of the extremely earthquake-stricken areas. Based on the third part of this analysis of the temporal trends of reconstruction efficiency in extremely earthquake-stricken areas, this section further analyzes the correlation between these main disaster-pregnancy environment and the reconstruction efficiency. This paper analyzes the spatial difference in reconstruction efficiency of extremely earthquake-stricken areas by defining the fluctuation index of reconstruction efficiency. The larger the fluctuation index, the worse the stability of extremely earthquakestricken areas in the process of postearthquake recovery and reconstruction. The formula is as follows: 


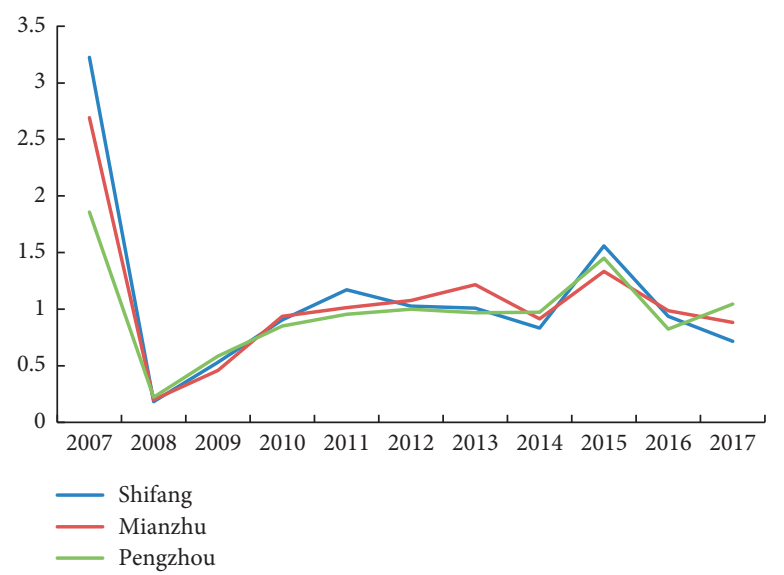

(a)

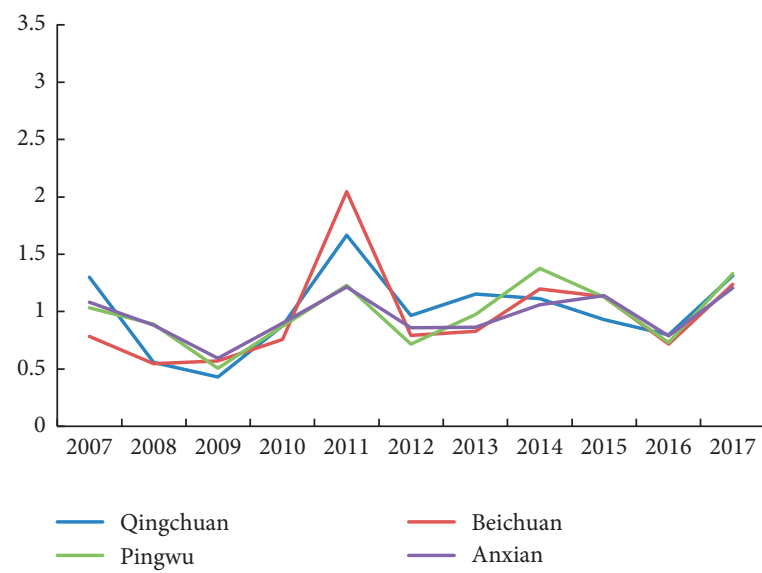

(c)

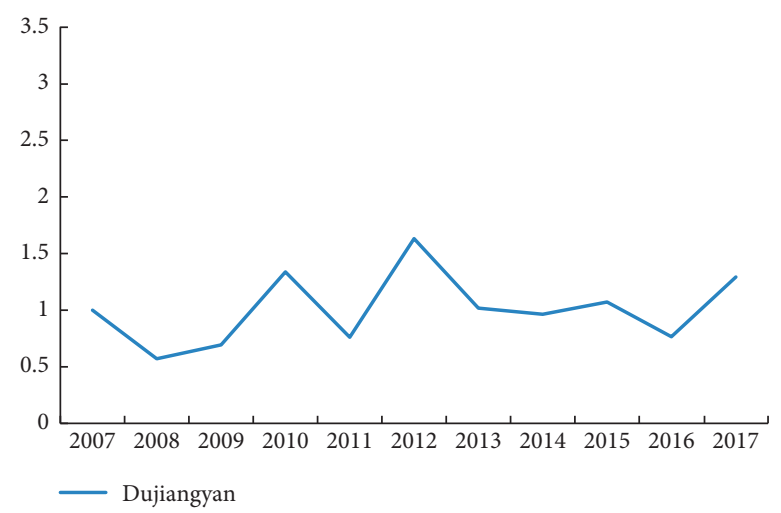

(b)

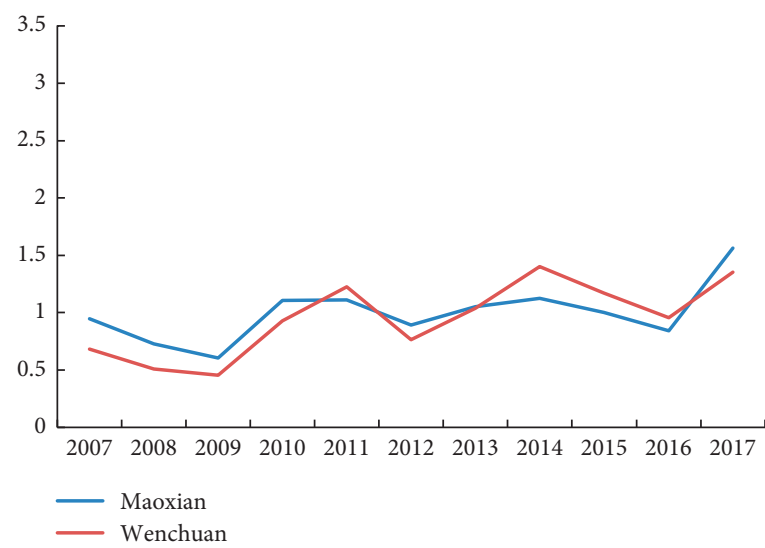

(d)

FIGURE 4: Category results of the TFP in the extremely earthquake-stricken areas.

$$
M_{\mathrm{TFP}}=\left(\frac{1}{n-1}\right) \sum_{i=1}^{n}\left(x_{i}-\bar{x}\right)^{2}
$$

In the formula, $M_{\mathrm{TFP}}$ represents the fluctuation index of reconstruction efficiency, $n=9$ (this paper mainly considers the situation of postearthquake recovery and reconstruction, so the time range considers 2009-2017), $x_{i}$ is the TFP in the $i$ year, and $\bar{x}$ represents the average value of TFP in 9 years. At the same time, for the above four categories, $\overline{M_{\text {TFP }}}$ is used to represent the average fluctuation index of the reconstruction efficiency of the extremely earthquake-stricken area in each category.

4.1. Correlation Analysis of Terrain Complexity and Reconstruction Efficiency in Extremely Earthquake-Stricken Areas.
The special terrain and geomorphic characteristics of the mountainous area that were severely affected make postearthquake reconstruction more difficult. The terrain complexity variable expresses the degree of surface relief and fold, which is an indispensable component of the study of topography and geomorphology. Therefore, on the basis of previous research on the mathematical model of terrain complexity [30], this paper uses ASTER GDEM 30 meter resolution elevation data and utilizes ArcGIS to cut the existing DEM grid data to obtain DEM data for the 10 extremely earthquake-stricken areas. Combined with the information entropy, this paper quantitatively describes the local roughness and undulation of the surface. The calculation formula of terrain information entropy is as follows [31]:

$$
H_{t}=-\sum_{i=1}^{M}\left(\frac{|h(i)|}{\sum_{i=1}^{M}|h(i)|}\right) \log _{2}\left(\frac{|h(i)|}{\sum_{i=1}^{M}|h(i)|}\right) \approx-\left(\sum_{i=1}^{M} \frac{|h(i)|}{\sum_{i=1}^{M}|h(i)|}\right)\left(\frac{|h(i)|}{\sum_{i=1}^{M}|h(i)|}-1\right) .
$$

In the formula, $H_{t}$ is terrain information entropy, $M$ is the total number of sliding window terrain data points, $h(i)$ is the elevation data for each point of the window, and $H_{t}$ reflects the average amount of information contained in the terrain of 


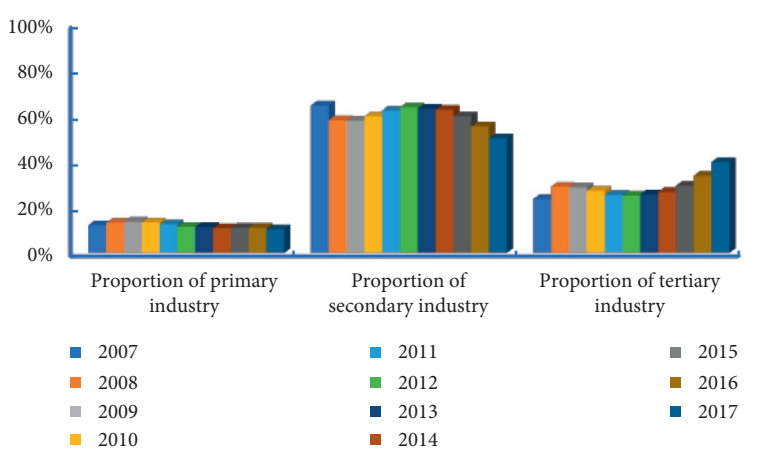

(a)

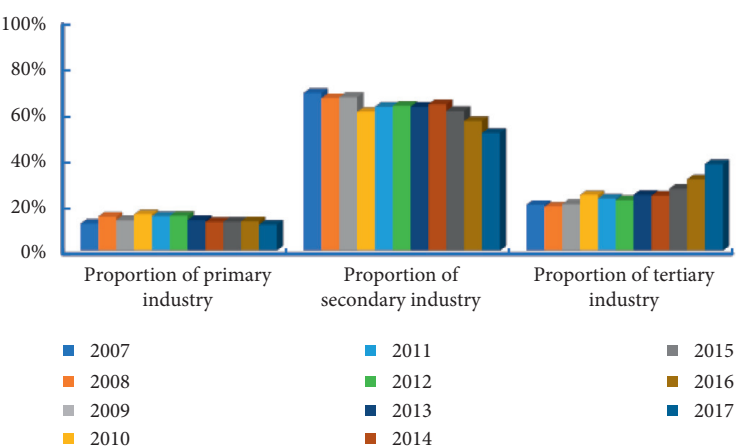

(b)

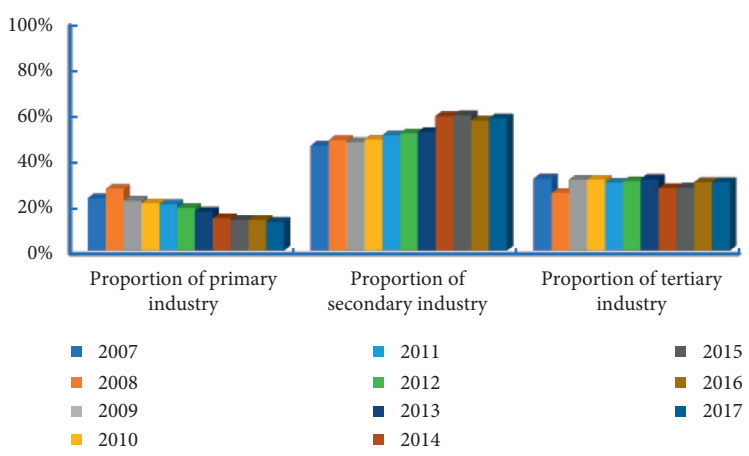

(c)

FIgUre 5: The industry proportion trend results of the first category: (a) Shifang; (b) Mianzhu; (c) Pengzhou.

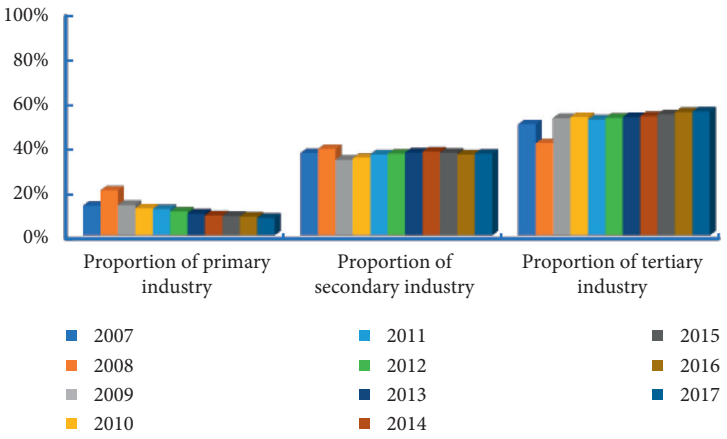

Figure 6: The industry proportion trend results of the second category (Dujiangyan).

the study areas. The more sharply the elevation value of the study area changes, the more complex the terrain is, the richer the information is, and the smaller $H_{t}$ is, vice versa.

As seen from the visualization results of the terrain complexity of the extremely earthquake-stricken areas in Figure 9, as a whole, the terrain and geomorphology of the 10 extremely earthquake-stricken disaster areas are of high complexity. The terrain in the southeast appears relatively gentle, which is consistent with the actual situation, indicating that the terrain information entropy can well reflect the complexity of the regional terrain. According to the four categories into which the extremely earthquake-stricken areas were divided, the average terrain information entropy
$\left(\overline{H_{t}}\right)$ was calculated and compared with $\left(\overline{M_{\mathrm{TFP}}}\right)$; the results are shown in Figure 10.

As seen from Figure 10, the overall trend is that the higher the $\overline{H_{t}}$ in the region is, the lower the $\overline{M_{\mathrm{TFP}}}$ is, showing a significant negative correlation. Taking the first category as an example, the terrain is relatively gentle, and its $\overline{H_{t}}$ value is the largest, and $\overline{M_{\text {TFP }}}$ is also the smallest. In the third category, $\overline{H_{t}}$ is the lowest, which means that the third category has the highest terrain complexity The landform change is relatively steep, and the $\overline{M_{\text {TFP }}}$ reaches 0.114 , which is the highest value among the four categories. This shows that the complex terrain is an important reason for the high fluctuation of reconstruction efficiency.

4.2. Correlation Analysis of Fault Density and Reconstruction Efficiency in Extremely Earthquake-Stricken Areas. As seen from the fault space distribution in Figure 5, the inclination of the fault zone is $45^{\circ} \mathrm{NE}$, and the tendency of the fault zone is NW. There are three major fault zones: the leading Longmenshan fault zone (Dujiangyan-Hanwang-Anxian), the central Longmenshan fault zone (Yingxiu-BeichuanGuanzhuang), and the back-Longmenshan fault zone (Wenchuan-Maoxian-Pingwu-Qingchuan). The three fault zones run through the 10 extremely earthquake-stricken areas. This paper combines the fault density to quantitatively describe the development degree of the fault zones. The specific formula for the fault density is as follows: 


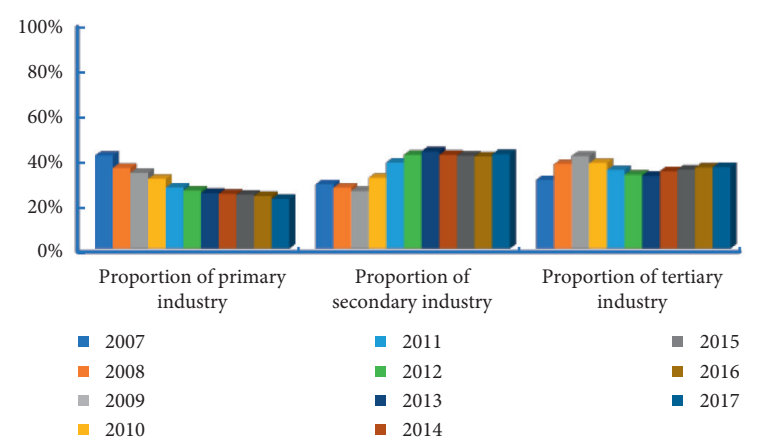

(a)

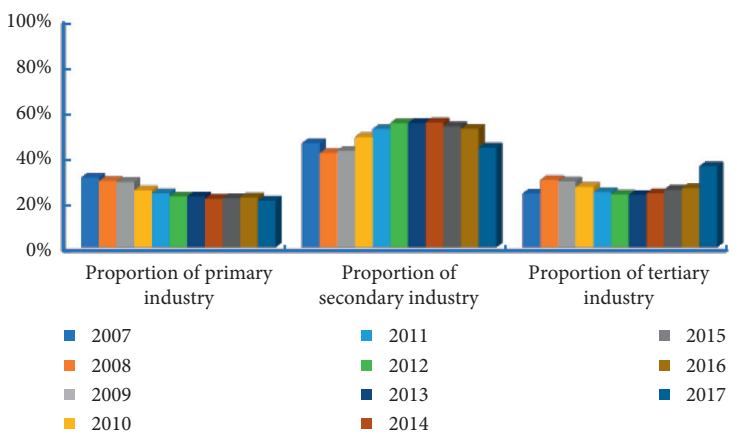

(c)

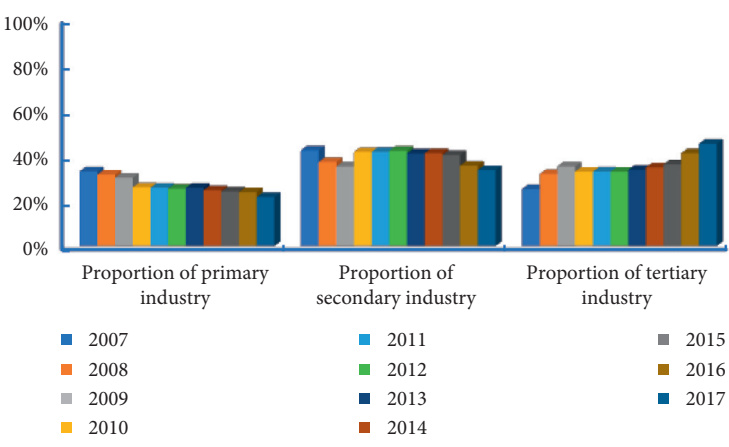

(b)

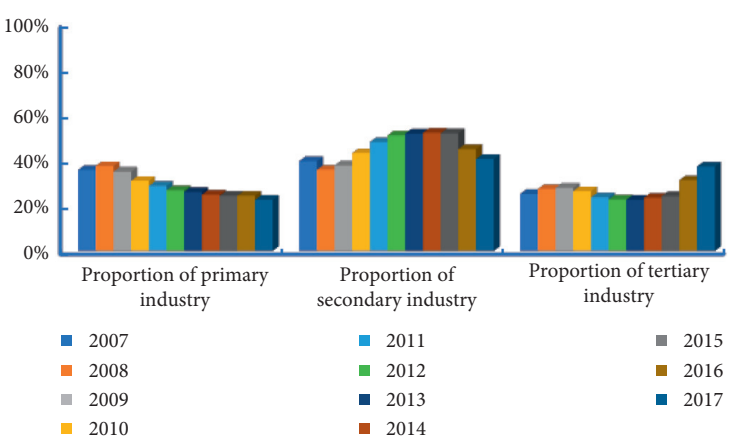

(d)

FIgure 7: The industry proportion trend results of the third category: (a) Qingchuan; (b) Beichuan; (c) Pingwu; (d) Anxian.

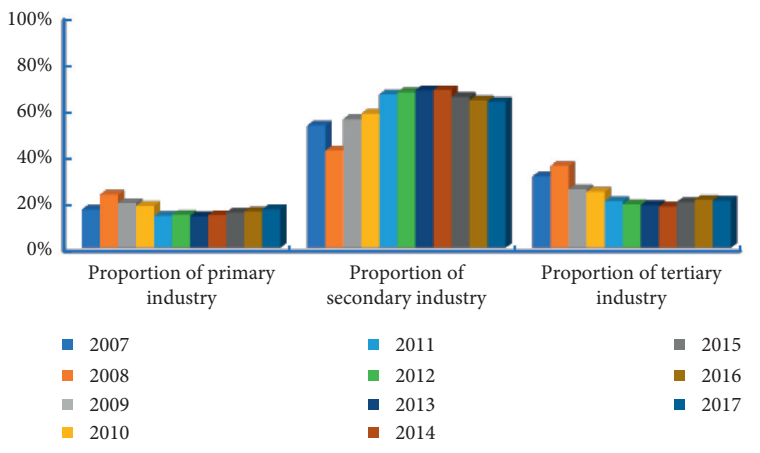

(a)

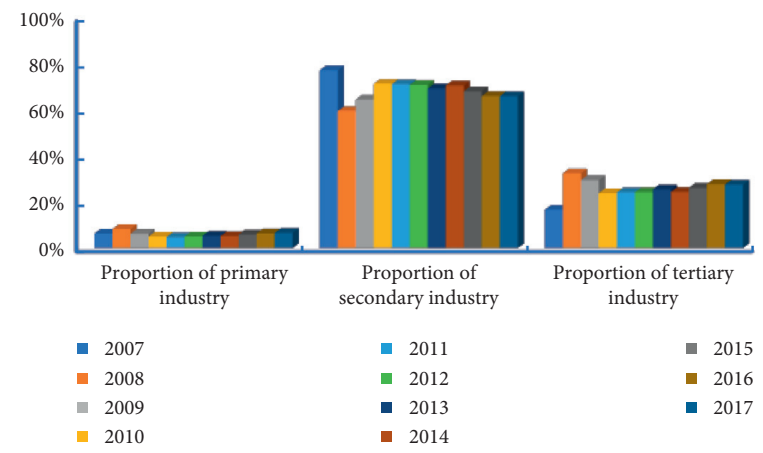

(b)

FIGURE 8: The industry proportion trend results of the fourth category: (a) Maoxian; (b) Wenchuan.

$$
D_{f}=\left(\frac{\sum L_{f}}{S}\right) \text {. }
$$

In the formula, $D_{f}$ refers to the fault density. $\sum L_{f}$ refers to the total length of the fault zones in each extremely earthquake-stricken areas, and $S$ refers to the area of extremely earthquake-stricken areas. The average fault density $\left(\overline{D_{f}}\right)$ of the four categories is calculated, and comparing and analyzing with $\overline{M_{\mathrm{TFP}}}$, the results are shown in Figure 11.

As seen from Figure $11, \overline{M_{\mathrm{TFP}}}$ and $\overline{D_{f}}$ have a certain correlation. Overall, the four categories of extremely earthquake-stricken areas can be divided into two groups (the first and second categories are the first group, and the third and fourth categories are two parts); for example, the third category of $\overline{D_{f}}$ is less than the first category and the second category, but the fluctuation is the highest; the second category of $\overline{D_{f}}$ is maximum $(0.0437)$ and $\overline{M_{\mathrm{TFP}}}$ is higher (0.098). The first part of $\overline{D_{f}}$ is relatively large, but the fluctuation is relatively small; the second part of $\overline{D_{f}}$ is relatively low, but the terrain complexity is high. It shows that the fault density has a certain influence on the fluctuation of extremely earthquake-stricken areas, but the influence degree is relatively low.

4.3. Correlation Analysis of River Network Density and Reconstruction Efficiency in Extremely Earthquake-Stricken Areas. As seen from the spatial distribution of the river systems 


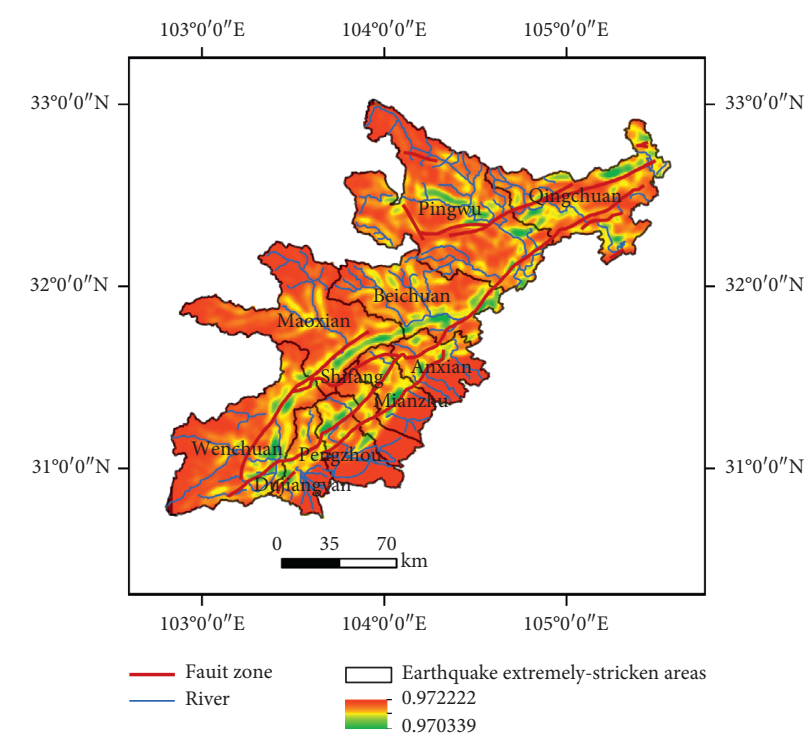

FIGURE 9: The graph of terrain complexity visualization result.

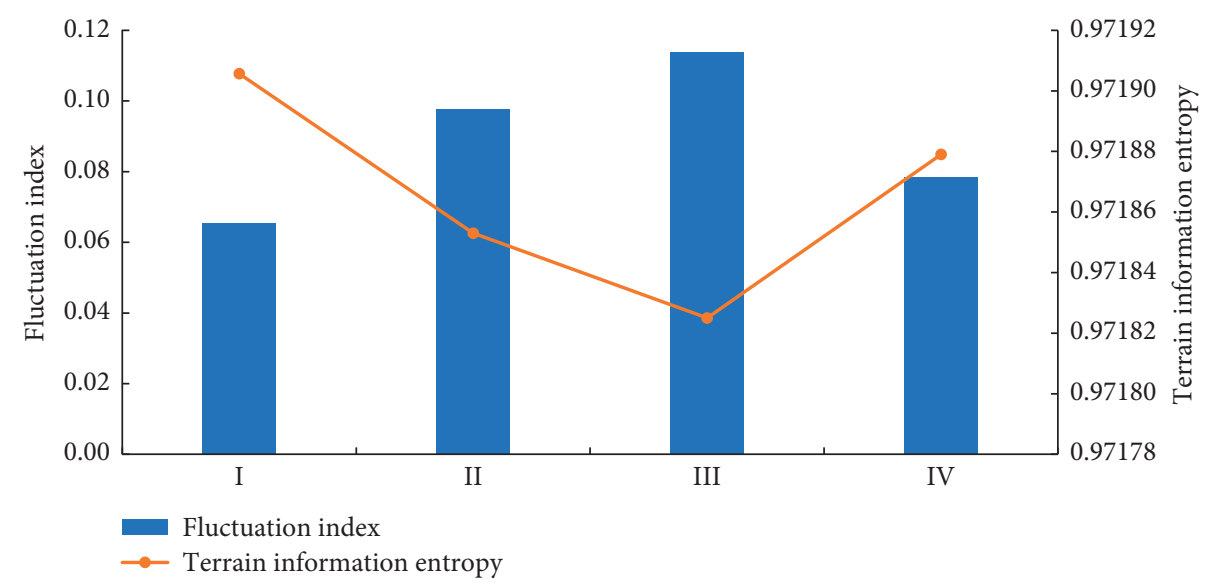

FIgURE 10: Relationship between the fluctuation index of reconstruction efficiency and terrain information entropy.

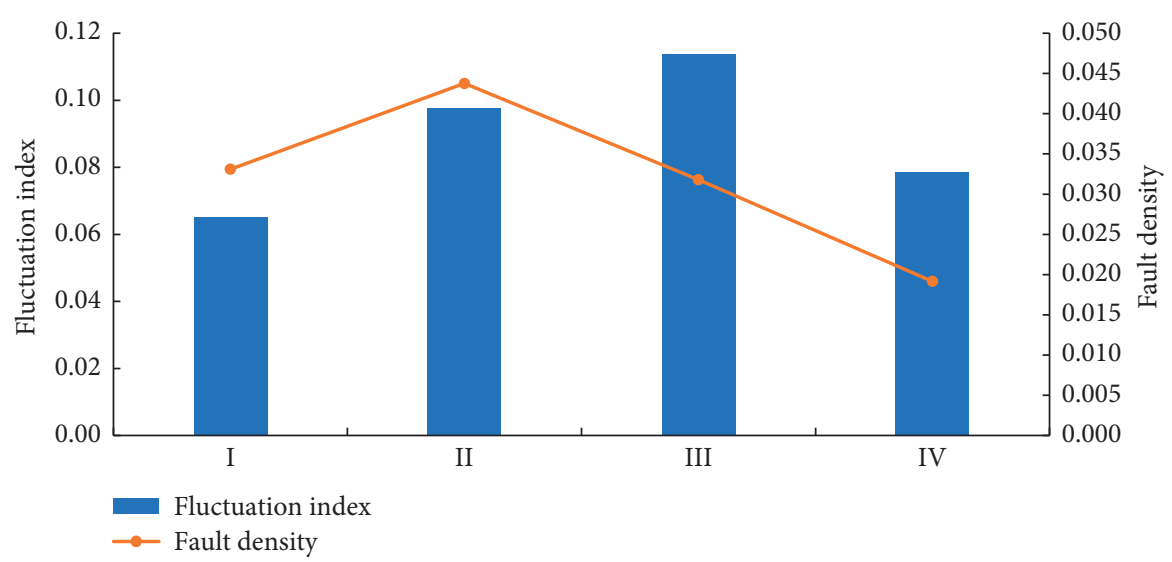

FIGURE 11: Relationship between fluctuation index of reconstruction efficiency and fault density. 


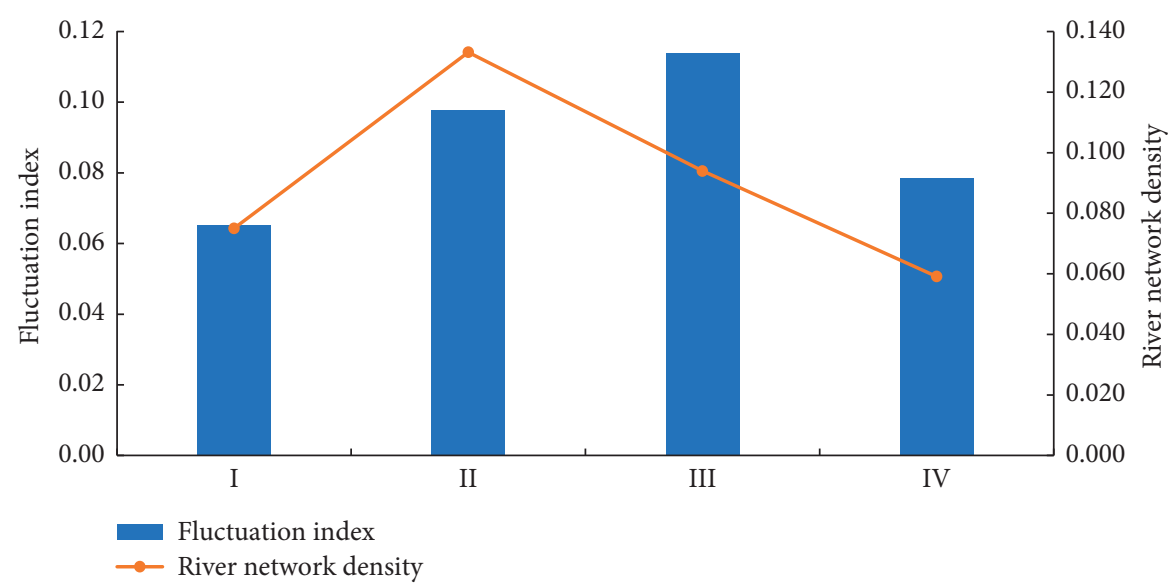

FigURE 12: Relationship between fluctuation index of reconstruction efficiency and river network density.

in Figure 2, the river systems of the 10 extremely earthquakestricken areas are relatively developed. In this paper, we define the river network density to reflect the development of rivers in the study area. The specific formula is as follows:

$$
D_{r}=\left(\frac{\sum H}{S}\right)
$$

In the formula, $D_{r}$ refers to the river network density, $\sum H$ refers to the total length of the river in each extremely earthquake-stricken areas, and $S$ refers to the area of each extremely earthquake-stricken areas. By calculating the average river network density $\left(\overline{D_{r}}\right)$ of the four categories and comparing and analyzing with $\bar{M}_{\mathrm{TFP}}$, the results are shown in Figure 12.

As seen from Figure 12, $\overline{M_{\mathrm{TFP}}}$ and $\overline{D_{r}}$ have a certain correlation. The second category has the highest $\overline{D_{r}}(0.1332)$. The third category $\overline{D_{r}}(0.0939)$ is inferior to the second category, but the third category of $\overline{M_{\mathrm{TFP}}}$ is larger than the second category. This shows that the second category of $\overline{M_{\text {TFP }}}$ may be more affected by the river network density than the third category, but the terrain complexity of the third category is higher, and it also shows that the river network density may be an important reason for the high fluctuation of reconstruction efficiency, but the impact of the river network density on the fluctuation of reconstruction efficiency is not as great as the impact of the topography on the fluctuation of reconstruction efficiency.

4.4. Degree of Impact Analysis of the Main Disaster-Pregnancy Environment and Fluctuation of Reconstruction Efficiency. The correlation coefficients of the fluctuation index of reconstruction efficiency and the three main disaster-pregnancy environmental factors are, respectively, calculated to describe the degree of impact of the three factors on the fluctuation of reconstruction efficiency. The calculation formula is as follows:
TABLE 2: Correlation coefficient results.

\begin{tabular}{cccc}
\hline & $\overline{M_{\mathrm{TFP}}}$ and $\overline{H_{t}}$ & $\overline{M_{\mathrm{TFP}}}$ and $\overline{D_{f}}$ & $\overline{M_{\mathrm{TFP}}}$ and $\overline{D_{r}}$ \\
\hline$|R|$ & 0.9975 & 0.3198 & 0.5648 \\
\hline
\end{tabular}

$$
|R|=\left|\frac{\sum_{i=1}^{n} \sum_{j=1}^{n}\left(X_{j}-X_{i}\right)\left(Y_{j}-Y_{i}\right)}{\left[\sum_{i=1}^{n} \sum_{j=1}^{n}\left(X_{j}-X_{i}\right)^{2} \sum_{i=1}^{n} \sum_{j=1}^{n}\left(Y_{j}-Y_{i}\right)^{2}\right]^{1 / 2}}\right| .
$$

In the formula, $|R|$ is the absolute value of the correlation coefficient between the fluctuation index of reconstruction efficiency and the three major disaster-pregnancy environmental factors, the value of $n$ is $4, X_{j}$ and $X_{i}$ are in each category $\overline{M_{\mathrm{TFP}}}$, and $Y_{i}$ and $Y_{j}$ are $\overline{H_{t}}$ or $\overline{D_{f}}$ or $\overline{D_{r}}$ in each category.

It can be seen from Table 2 that the correlation coefficient of the fluctuation of reconstruction efficiency and the terrain information entropy is the highest and smallest for the fault density. At the same time, combined with Figures 11 and 12, in the overall trend, the trend of river network density and fault density are basically consistent, but from the numerical point of view, the river network density is much greater than the fault density (close to 3 times), indicating that the river systems have a higher degree of development in the $10 \mathrm{ex}$ tremely earthquake-stricken areas. It can be seen from the fluctuation of reconstruction efficiency and the degree of influence between the three that the complex topography and the development of the river systems that the fault density is an important reason for the high fluctuation of reconstruction efficiency. Because of the continuous impact of the effects of earthquake-induced hazards, the duration of the effects is approximately 20 years [28], which has an important impact on the social-economic development of the extremely earthquake-stricken areas in the postearthquake reconstruction process, and further illustrates that the fluctuation of postearthquake reconstruction efficiency and the effects of earthquake-induced hazards are closely related. 


\section{Discussion and Conclusion}

This paper focuses on the evaluation of the postearthquake reconstruction efficiency among extremely earthquakestricken areas that were severely affected by the Wenchuan earthquake. From the perspective of the inputs and outputs, a reconstruction efficiency evaluation model of the extremely earthquake-stricken areas based on the DEAMalmquist index was built and used to extract the three major disaster-pregnancy environmental factors, namely, the topography, fault zones, and river systems of the extremely earthquake-stricken areas, and to analyze the reconstruction efficiency of these 10 extremely earthquakestricken areas from the spatiotemporal perspective, the results can be recognized as follows.

First, the overall analysis of the TFPs of 10 extremely earthquake-stricken areas that had been affected by the Wenchuan earthquake showed that the TFPs in 2011 had basically recovered to preearthquake levels, mainly due to the interaction of external forces, such as postearthquake aid, while later, there were small fluctuations. The reason for this was partly due to the gradual decrease of external forces, but it was also closely related to the effects of earthquakeinduced hazards. At the same time, judging from the temporal trends in the postearthquake recoveries, there are still areas for further improvement in reconstruction efficiency in the 10 extremely earthquake-stricken areas.

Second, the analysis of the difference in postearthquake reconstruction efficiency in the 10 extremely earthquakestricken areas showed that the "convergence effect" did not appear. According to the TFP analysis, the categories could be divided into four categories. The first category of Shifang, Mianzhu, and Pengzhou has strong industrial adjustment capabilities and shows a strong ability to cope with earthquake-induced hazards. The second category of Dujiangyan mainly uses the tertiary industry as its pillar industry, but it is greatly affected by earthquake-induced hazards during the postearthquake reconstruction. The third category of Qingchuan, Beichuan, Pingwu, and Anxian is extremely susceptible to earthquake-induced hazards, with their primary industries showing a significant downward trend after the earthquake, and their TFP dropped sharply after the external force subsided. Although the TFP of the fourth category of Wenchuan and Maoxian fluctuated after the earthquake, the fluctuation was relatively small. The reason was that the reconstruction efficiency was closely related to the characteristics of the resources in the extremely earthquake-stricken areas.

Furthermore, by considering the disaster-pregnancy environment in the extremely earthquake-stricken area and extracting the three major disaster-pregnancy environmental factors, such as the topography, fault zones, and river systems, the degree of correlation between these factors and the postdisaster reconstruction efficiency in the extremely earthquake-stricken area was analyzed. The results showed that the correlation coefficient of the fluctuation of reconstruction efficiency and the terrain information entropy is the highest (0.9975), and the correlation coefficient of the fault density is the smallest (0.3198). Terrain complexity is an important reason for the high fluctuation of reconstruction efficiency; at the same time, the river network density has a certain effect on the fluctuation of the reconstruction efficiency in extremely earthquake-stricken areas, but the degree of impact is relatively low, and the impact of fault density is minimal. The fluctuation of postearthquake reconstruction efficiency in the extremely earthquake-stricken areas is closely related to the effects of earthquake-induced hazards. Therefore, to improve the reconstruction efficiency of the extremely earthquake-stricken areas, the adjustment measures that promote local advantages should be fully utilized to mitigate the lasting effects of earthquake-induced hazards.

\section{Data Availability}

The data used to support the findings of this study are available from the corresponding author upon request.

\section{Conflicts of Interest}

The authors declare that there are no conflicts of interest.

\section{Acknowledgments}

This study was supported by the National Key R\&D Program of China (2018YFC0604105), Scientific Research Fund of Sichuan Province Education Department (Project no. 18ZB0062), and Sichuan Science and Technology Program (2019JDKY0017 and 2019YJ0401).

\section{References}

[1] X. Li, Z. Li, J. Yang et al., "Spatiotemporal characteristics of earthquake disaster losses in China from 1993 to 2016," Natural Hazards, vol. 94, no. 2, pp. 843-865, 2018.

[2] J. Xu and Y. Lu, "Meta-synthesis pattern of post-disaster recovery and reconstruction: based on actual investigation on 2008 Wenchuan earthquake," Natural Hazards, vol. 60, no. 2, pp. 199-222, 2012.

[3] B. Liu, S. Y. Han, H. Gong, Z. L. Zhou, and D. Zhang, "Disaster resilience assessment based on the spatial and temporal aggregation effects of earthquake-induced hazards," Environmental Science and Pollution Research, vol. 27, no. 23, pp. 29055-29067, 2020.

[4] J. Fan, J. X. Chen, B. Tian et al., "Rapid assessment of secondary disasters induced by the Wenchuan earthquake," Computing in Science \& Engineering, vol. 12, no. 1, pp. 10-19, 2010.

[5] O. Zhi, "Impact assessment of Wenchuan earthquake on ecosystems," Acta Ecologica Sinica, vol. 28, no. 12, pp. 5801-5809, 2008.

[6] G. Wang, "Impact assessment of Wenchuan earthquake on ecological environment in the nature reserves and the strategy," Sichuan Environment, vol. 28, no. 3, pp. 46-49, 2009.

[7] D. M. Abramson, T. Stehling-Ariza, Y. S. Park, L. Walsh, and D. Culp, "Measuring individual disaster recovery: a socioecological framework," Disaster Medicine and Public Health Preparedness, vol. 4, pp. 46-54, 2010. 
[8] C. Burton, J. T. Mitchell, and S. L. Cutter, "Evaluating postKatrina recovery in Mississippi using repeat photography," Disasters, vol. 35, no. 3, pp. 488-509, 2011.

[9] F. L. Bates and W. G. Peacock, "Measuring disaster impact on household living conditions: the domestic assets approach," International Journal of Mass Emergencies and Disasters, vol. 10, no. 1, pp. 133-160, 1992.

[10] C. Shen, "The empirical study on the post-disaster reconstruction capacity and its performance: county-level government in Wenchuan earthquake as an example," China Population, Resources and Environment, vol. 24, no. 8, pp. 156-161, 2014.

[11] H. Liu, D. Zhang, Q. Wei, and Z. Guo, "Comparison study on two post-earthquake rehabilitation and reconstruction modes in China," International Journal of Disaster Risk Reduction, vol. 23, pp. 109-118, 2017.

[12] M. Polese, M. Di Ludovico, and A. Prota, "Post-earthquake reconstruction: a study on the factors influencing demolition decisions after 2009 L'Aquila earthquake," Soil Dynamics and Earthquake Engineering, vol. 105, pp. 139-149, 2018.

[13] Y. Chang, S. Wilkinson, D. Brunsdon, E. Seville, and R. Potangaroa, "An integrated approach: managing resources for post-disaster reconstruction," Disasters, vol. 35, no. 4, pp. 739-765, 2011.

[14] W. Tang, J. Li, Z. Lei, E. Wang, and W. Shen, "Creating socialphysical resilience to natural disasters: lessons from the Wenchuan earthquake," Natural Hazards, vol. 79, no. 2, pp. 1111-1132, 2015.

[15] S. Malmquist, "Index numbers and indifference surfaces," Trabajos De Estadistica, vol. 4, no. 2, pp. 209-242, 1953.

[16] R. W. Shepherd, Theory of Cost and Production Functions, Princeton University Press, Princeton, NJ, USA, 1970.

[17] D. W. Caves, L. R. Christensen, and W. E. Diewert, "The economic theory of index numbers and the measurement of input, output, and productivity," Econometrica, vol. 50, no. 6, pp. 1393-1414, 1982.

[18] R. Färe, S. Grosskopf, and W. L. Weber, "Measuring school district performance," Public Finance Quarterly, vol. 17, no. 4, pp. 409-428, 1989.

[19] A. Charnes, W. W. Cooper, and E. Rhodes, "Measuring the efficiency of decision making units," European Journal of Operational Research, vol. 2, no. 6, pp. 429-444, 1978.

[20] R. Fare, S. Grosskopf, M. Norris, and Z. Zhang, "Productivity growth, technical progress, and efficiency change in industrialized countries," American Economic Review, vol. 84, no. 1, pp. 66-83, 1994.

[21] M. Linna, "Measuring hospital cost efficiency with panel data models," Health Economics, vol. 7, no. 5, pp. 415-427, 1998.

[22] J. Ventura, E. GonzáLez, and A. Cárcaba, "Efficiency and program-contract bargaining in Spanish public hospitals," Annals of Public and Cooperative Economics, vol. 75, no. 4, pp. 549-573, 2004.

[23] M. Kortelainen, "Dynamic environmental performance analysis: a Malmquist index approach," Ecological Economics, vol. 64, no. 4, pp. 701-715, 2008.

[24] A. G. Assaf and C. Barros, "Performance analysis of the Gulf hotel industry: a Malmquist index with bias correction," International Journal of Hospitality Management, vol. 30, no. 4, pp. 819-826, 2011.

[25] M. Johannes and S. Semida, "Capturing energy efficiency in European iron and steel production-comparing specific energy consumption and Malmquist productivity index," Energy Efficiency, vol. 7, no. 6, pp. 955-972, 2014.
[26] M. Varmaghani, A. H. Meshkini, F. Farzadfar et al., "Evaluation of productivity in Iranian pharmaceutical companies: a DEA-based Malmquist approach and panel data analysis," Journal of Research in Pharmacy Practice, vol. 4, no. 2, pp. 51-56, 2015.

[27] N. Amani, H. B. Valami, and A. Ebrahimnejad, "Application of Malmquist productivity index with carry-overs in power industry," Alexandria Engineering Journal, vol. 57, no. 4, pp. 3151-3165, 2018.

[28] R. Huang, "After effect of geohazards induced by the Wenchuan Earthquake," Engineering Geology, vol. 19, no. 2, pp. 145-151, 2011, in Chinese.

[29] H. H. Gao, X. J. Pei, S. H. Cui, L. Zhu, and Y. F. Liang, "Geological hazards after earthquake in Wenchuan earthquake area: distribution and evolvement features," Journal of Yangtze River Scientific Research Institute, vol. 36, no. 8, pp. 73-80, 2019, in Chinese.

[30] Y. Zhou, G. A. Tang, T. Zhang, M. L. Luo, and Y. N. Jia, "Spatial pattern of terrain feature lines of Loess gully-hill region," Arid Land Geography, vol. 33, no. 1, pp. 106-111, 2010.

[31] B. Liu, X. Chen, Z. Zhou, M. Tang, and S. Li, "Research on disaster resilience of earthquake-stricken areas in Longmenshan fault zone based on GIS," Environmental Hazards, vol. 19, no. 1, pp. 50-69, 2020. 